Review

\title{
A Systematic Review of Enterprise Innovation Ecosystems
}

\author{
Lijie Feng ${ }^{1,2, *}$, Jiarui Lu ${ }^{1}$ and Jinfeng Wang ${ }^{2}(\mathbb{D}$ \\ 1 School of Management Engineering, Zhengzhou University, Zhengzhou 450001, China; 18351926126@163.com \\ 2 School of Economic \& Management, Shanghai Maritime University, Shanghai 201306, China; \\ wangjinfeng@shmtu.edu.cn \\ * Correspondence: ljfeng@shmtu.edu.cn
}

check for

updates

Citation: Feng, L.; Lu, J.; Wang, J. A Systematic Review of Enterprise Innovation Ecosystems. Sustainability 2021, 13, 5742. https://doi.org/ $10.3390 /$ su13105742

Academic Editor: Fabrizio D'Ascenzo

Received: 15 April 2021

Accepted: 17 May 2021

Published: 20 May 2021

Publisher's Note: MDPI stays neutral with regard to jurisdictional claims in published maps and institutional affiliations.

Copyright: (c) 2021 by the authors. Licensee MDPI, Basel, Switzerland. This article is an open access article distributed under the terms and conditions of the Creative Commons Attribution (CC BY) license (https:// creativecommons.org/licenses/by/ $4.0 /)$.

\begin{abstract}
With rapid changes and increasing uncertainty in the market environment, enterprise innovation ecosystems (EIEs) have increasingly been promoted in the past decade. Nevertheless, research on EIEs has fallen into a fuzzy state. Scholars have scattered views on the subject and have not systematically classified it, leading to a discussion regarding its conceptual rigor and comprehensive analysis. The purpose of this article is to conduct integrative research on EIEs and to examine all the relevant issues of existing views. This study screened all relevant topics in the past decade through the WOS database and identified significant journal articles. By reviewing and sorting out the relevant thematic literature from 2011 to 2020 and performing keyword cluster analysis, the research focus and hot spots of EIEs are determined. The entity structure, main types, dynamic mechanism, and evolution mechanism of EIEs were elaborated, and the definition of an EIE is finally determined. Through an analysis of the emerging viewpoints of EIEs, the hot spots of this topic are discussed. These streams provide opportunities for further research to consolidate the concepts of EIEs.
\end{abstract}

Keywords: innovation ecosystems; cluster analysis; perspective analysis; theory evolution; systematic review

\section{Introduction}

Research on ecosystems and their effects on firm outcomes has only recently emerged. Unlike the previous static and government-supervised innovation system concepts, "innovation ecosystems" have a "dynamic and flexible collaborative structure" [1]. With rapid changes in the business environment and the increasing complexity and uncertainty of tasks, future competition no longer involves confrontation between individual companies. Fierce competition among firms promotes the transformation of innovation activities from mechanic to ecological and organic [2]. Competition within an ecosystem and among ecosystems is increasingly fierce. Thus, the sustainability of firms depends on the overall development of ecosystems.

At present, innovation ecosystems have become the focus of enterprise attention. Some leading companies around the world (such as Apple, IBM, Procter \& Gamble, Siemens, Microsoft, Google, and Haier [3]) have introduced new innovation paradigms and established dynamic and open innovation ecosystems centered on enterprises. Firms actively cooperate with other actors within ecosystems. The carrying out of resource sharing and information interaction has produced countless influential innovations in industries [4], which not only enhances the growth potential and innovation capabilities of a company's own business but, more importantly, creates value for consumers and achieves market competitive advantages. The construction of the innovation ecosystem model is related to specific regional space, such as national innovation ecosystems (NIEs), regional innovation ecosystems (RIEs), industrial innovation ecosystems (IIEs), and enterprise innovation ecosystems (EIEs) [2]. Due to the different starting points of scholars, the existing research is relatively scattered and lacks a common knowledge base. In recent years, there has also 
been a lack of time-effective and systematic combinations of the research status, evolution trend, and research gaps in terms of EIEs in the academic world. Therefore, the above content constitutes the research focus of this article, which has important enlightening significance both in theory and in practice. To fill this gap, this article applies a systematic literature review and combines a hybrid method consisting of bibliometric analysis and content analysis, covering 85 journal articles from 2011 to 2020. This research attempts to find the research focus and frontier areas through keyword cluster analysis and identifies several important research questions:

RQa. How can the position of an EIE be clarified in the overall innovation ecosystems?

$\mathrm{RQb}$. What is an EIE, including its entity, type, evolution mechanism, and motivation mechanism?

RQc. How is an EIE defined?

RQd. What is the latest research progress and future trends of EIEs?

In fact, scholars have discussed each of the above issues to varying degrees. Jiang et al. investigate how an innovation ecosystem is built and coordinated from a core-firm-based view [2]. Yin et al. elaborate on the birth, definition, and characteristics of a sustainable and smart product-innovation ecosystem [5]. Granstrand et al. conduct a conceptual review and propose a new definition of the innovation ecosystems [6]. This research integrates existing opinions and systematically answers the above questions based on certain related topics. To answer RQc, this work first systematically answers RQa and RQb. By clarifying their position in innovation ecosystems, NIEs, RIEs, IIEs, and EIEs can be clearly distinguished. In this way, the relationship between EIEs and the overall innovation ecosystem's distinction and connection is very clear. Then, based on the composition of the overall innovation ecosystem and the results of keyword analysis, RQb is systematically answered, and the entity composition, main types, dynamic mechanism, and evolution mechanism of EIEs are systematically and comprehensively summarized. After RQa and $\mathrm{RQb}$ are clarified, the definition of an EIE also becomes clear. Finally, according to the frontier vocabulary of keywords and a summary of the emerging perspectives of 85 documents, frontier analysis of EIEs is carried out.

Based on the scattered research of scholars, this article comprehensively organizes the existing literature on EIEs, establishes a common knowledge base, and provides a definition of an EIE. This work explores the research of the past decade, presents the re-search status and development trend, fills the current research gap, and provides a considerate arrangement and foundation for future scholars to study this topic.

The remainder of this study is arranged as follows. Section 2 describes this research methodology and literature review process, including data collection, data analysis, and data synthesis. Section 3 introduces the clarification of the innovation ecosystems, the entities, types, motivating mechanism and evolution of EIEs, and the definition of EIEs, and identifies the emerging research on EIEs. Section 4 explains the lack of significant results and discusses theoretical and practical implications and policy recommendations. Section 5 discusses conclusions, limitations, and future directions.

\section{Methodology}

This research focuses on EIEs. A systematic review is needed to search and select the relevant literature on EIEs in three stages: data collection, analysis, and synthesis [7]. The systematic review of the innovation ecosystem literature in this research includes bibliometrics and content analysis. The combination of the two methods aims to determine literature trends, discuss the most frequent topics and fields, and possible gaps in the literature [8].

\subsection{Data Collection}

The bibliometric database was extracted by Thomson Reuters from the ISI Web of Science database, which was chosen because it provides a feature through which a set of metadata, such as abstracts, authors, institutions, the number of citations, citations, and 
journal impact factors, can be collected, which are all necessary for bibliometric analysis [8]. The literature data come from the Web of Science (WOS) core collection database (data collection took place on 31 December 2020). This systematic literature review depends upon a reproducible, structured, and transparent method.

We used a four-stage selection process to identify relevant articles from these journals.

First, we searched all articles from 2011 to 2020 that were available online, using the Web of Science database. Consistent with prior approaches to identify relevant articles [8], we performed keyword searches and retained those 634 articles that contained the word "innovation ecosystem" and/or any of the phrases "enterprise or firm or company or business or corporation" or "business ecosystem" ${ }^{*}$ in either their titles, abstracts or full texts.

Second, the "Discipline Category" was chosen to be "Management or Business or Economics or Operations Research Management Science", and 427 articles were obtained after refining.

Third, the "Document Type" was chosen to be "Article \& Review". We limited the review to peer-reviewed journal articles, omitting books, book chapters, and other nonrefereed publications because journal articles are considered validated knowledge and are likely to have the highest impact in this field. Moreover, 295 articles were obtained after refining.

Fourth, we employed a two-tier review method for systematic evaluation, in order to reduce subjective interpretation bias [9]. The authors read each of the 295 articles and independently analyzed the abstract, research focus, data and methods, and results. The individual assessments were then combined and synthesized. Eighty-five articles satisfied this requirement in this process. Thus, 85 articles remained for analysis. The data retrieval and selection process are shown in Figure 1.

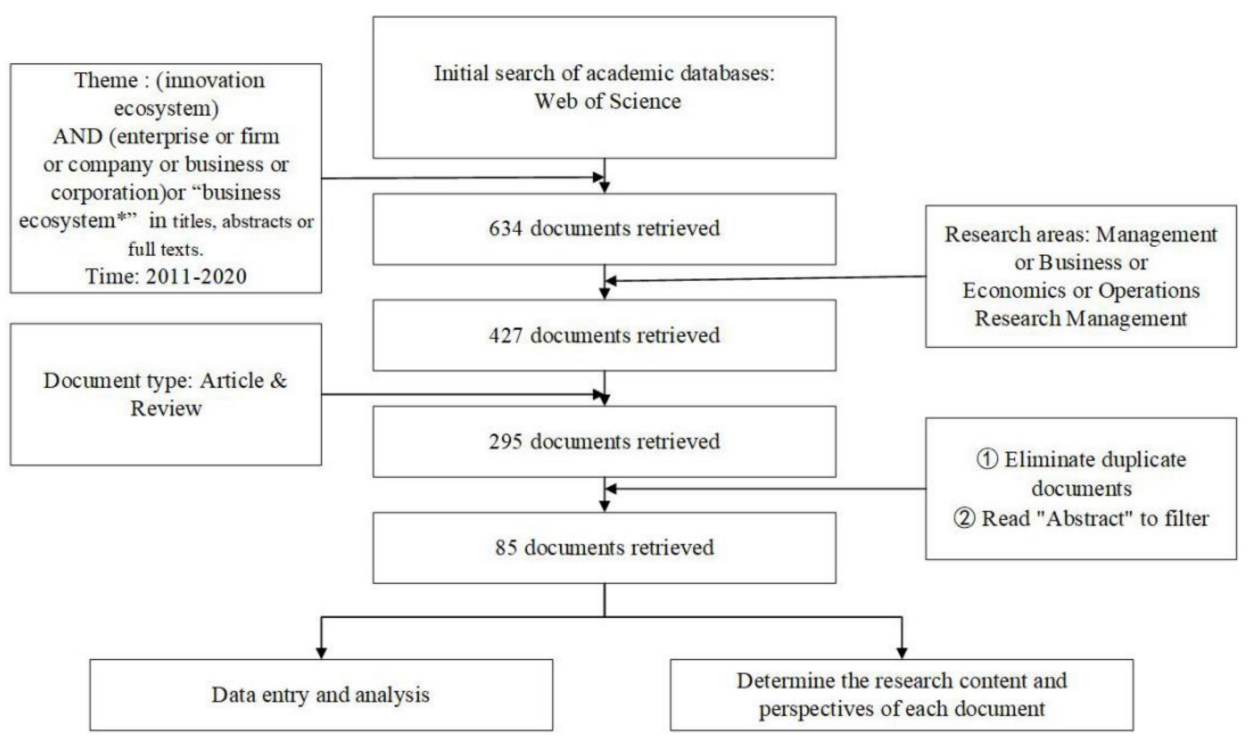

Figure 1. Data collection process.

\subsection{Data Analysis}

2.2.1. Descriptive Analysis

(1) Time distribution analysis of the research literature

The number of annual publications generally reflects the importance of the research field and the degree of attention it receives. This paper conducts a statistical analysis of the 85 documents finally identified according to the year distribution, as shown in Figure 2. During the period 2011-2020, the number of research documents on EIEs showed a stairlike upward trend. In terms of time, during the period 2011-2017, the number of relevant documents was relatively small, and the research was dominated by the theory of business ecosystems, which was in its early stage of research on the overall innovation ecosystem; 
from 2018 to 2020, the amount of relevant literature increased sharply, and the research on EIEs entered a stage of rapid development.

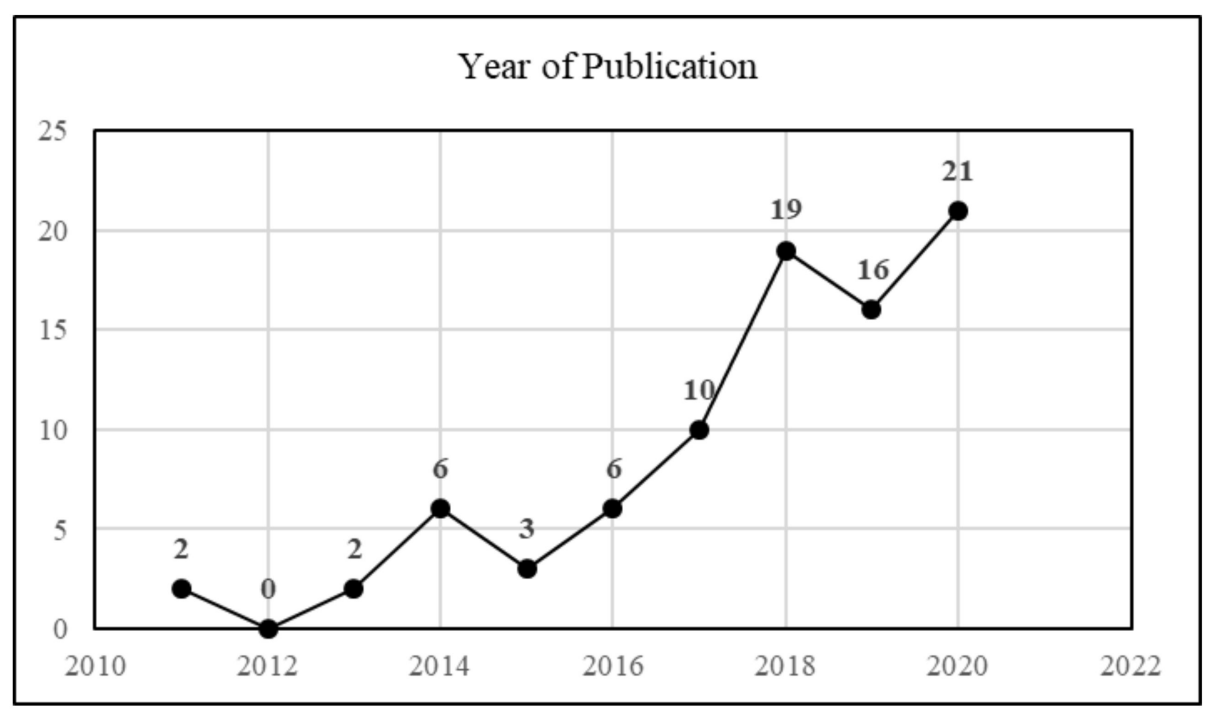

Figure 2. Year of publication of the selected articles.

(2) Analysis of Journal Distribution of the Research Literature

Regarding the collation and statistics of academic journals, the journals with only one article are omitted in Table 1. Most of the articles in the final dataset are from the Technological Forecasting \& Social Change category, and more than five articles are from te Sustainability and Technovation.

Table 1. Journals in which the selected articles were published.

\begin{tabular}{cc}
\hline Journals & Number \\
\hline Technological Forecasting \& Social Change & 18 \\
Sustainability & 7 \\
Technovation & 5 \\
Journal of Cleaner Production & 4 \\
Industrial Marketing Management & 2 \\
International Journal of Technology & 2 \\
Management & 2 \\
Research Policy & 2 \\
\hline Strategic Management Journal & 2 \\
\hline
\end{tabular}

(3) Method used in selected articles

Figure 3 shows the distribution of the methods used in the studied articles, of which qualitative research is the most frequent method used; these articles mostly consist of case studies, followed by literature reviews. 


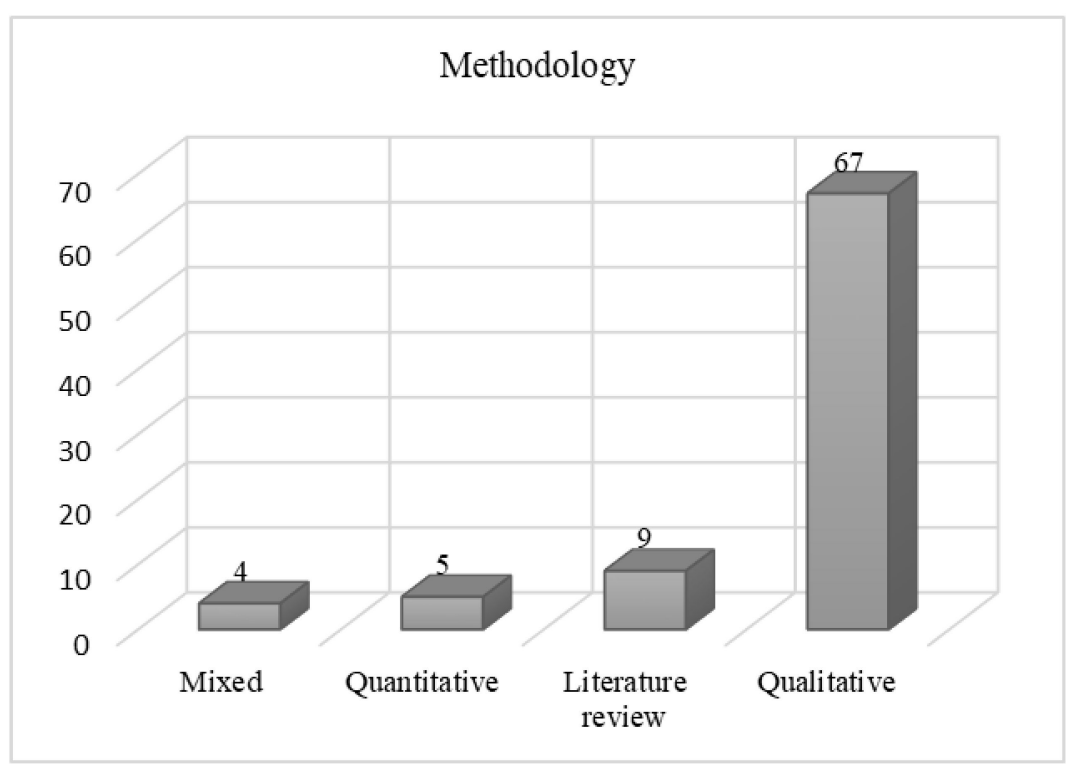

Figure 3. Methodology.

(4) Highly cited literature analysis

Highly cited literature is often classic literature with important new theories or major theoretical innovations, and thus, it is very important to sort out the development context of a certain research field. Of the sources reviewed, nine are highly cited each year, as shown in Table 2. The purpose of the study, research design, and key findings of these 9 papers are in Table A1 in Appendix A.

Table 2. Highly Cited Literature per Each Year.

\begin{tabular}{|c|c|c|c|}
\hline Serial Number & Title of Top Cited Articles & Year & Number of Citations \\
\hline 1 & $\begin{array}{l}\text { Connecting local entrepreneurial ecosystems to global innovation } \\
\text { networks: open innovation, double networks and knowledge } \\
\text { integration }\end{array}$ & 2011 & 51 \\
\hline 2 & $\begin{array}{c}\text { Entrepreneurship in Innovation Ecosystems: Entrepreneurs' } \\
\text { Self-Regulatory Processes and Their Implications for New } \\
\text { Venture Success }\end{array}$ & 2013 & 355 \\
\hline 3 & Industry Platforms and Ecosystem Innovation & 2014 & 434 \\
\hline 4 & $\begin{array}{l}\text { Innovation through institutionalization: A service ecosystems } \\
\text { perspective }\end{array}$ & 2015 & 226 \\
\hline 5 & Innovation ecosystems: A critical examination & 2016 & 147 \\
\hline 6 & Ecosystem as Structure: An Actionable Construct for Strategy & 2017 & 287 \\
\hline 7 & $\begin{array}{l}\text { Unpacking the innovation ecosystem construct: Evolution, gaps } \\
\text { and trends }\end{array}$ & 2018 & 68 \\
\hline 8 & $\begin{array}{l}\text { Managing ecosystems for service innovation: A dynamic } \\
\text { capability view }\end{array}$ & 2019 & 55 \\
\hline 9 & Innovation ecosystems: A conceptual review and a new definition & 2020 & 22 \\
\hline
\end{tabular}

\subsubsection{Keyword Cluster Analysis}

This article uses bibliometric visualization methods to help this study find the most critical information and understand the objective development of EIEs. VOSviewer is a powerful visualization software. It uses document co-citation and co-citation relationships as the basic principle. Moreover, it builds and displays bibliometric graphs based on the difference in distance, size, and density between nodes. Keyword clusters are used 
to identify the concepts related to EIEs. Each keyword appears 3 times and is cited as meeting the criteria of this study [8]. The identified keywords are related to each other, and the strength of this relationship corresponds to the strength of the relationship between concepts related to EIEs. The color of an element represents the cluster to which it belongs, and different clusters are represented by different colors, as shown in Figure 4 .

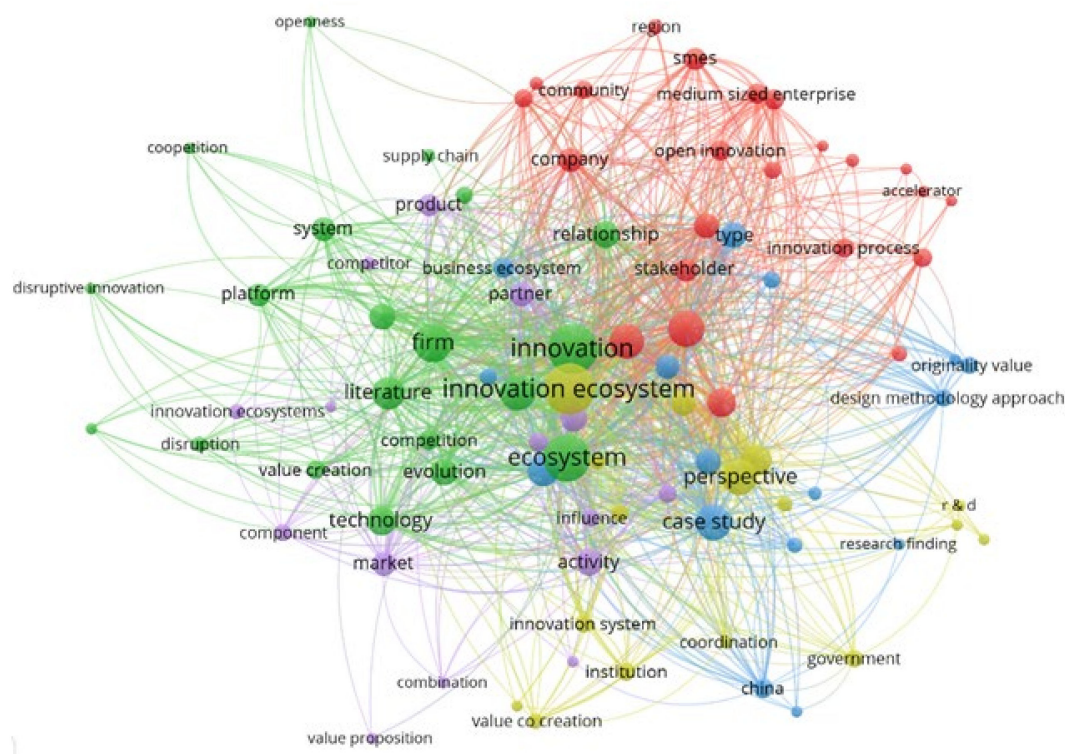

Figure 4. Keyword network visualization.

The feature of overlay visualization that makes it different from network visualization is that users can assign different colors to nodes through the score or color in the map file according to their own research needs as in Figure 5. By default, the average year of the keyword takes the score value for color mapping.

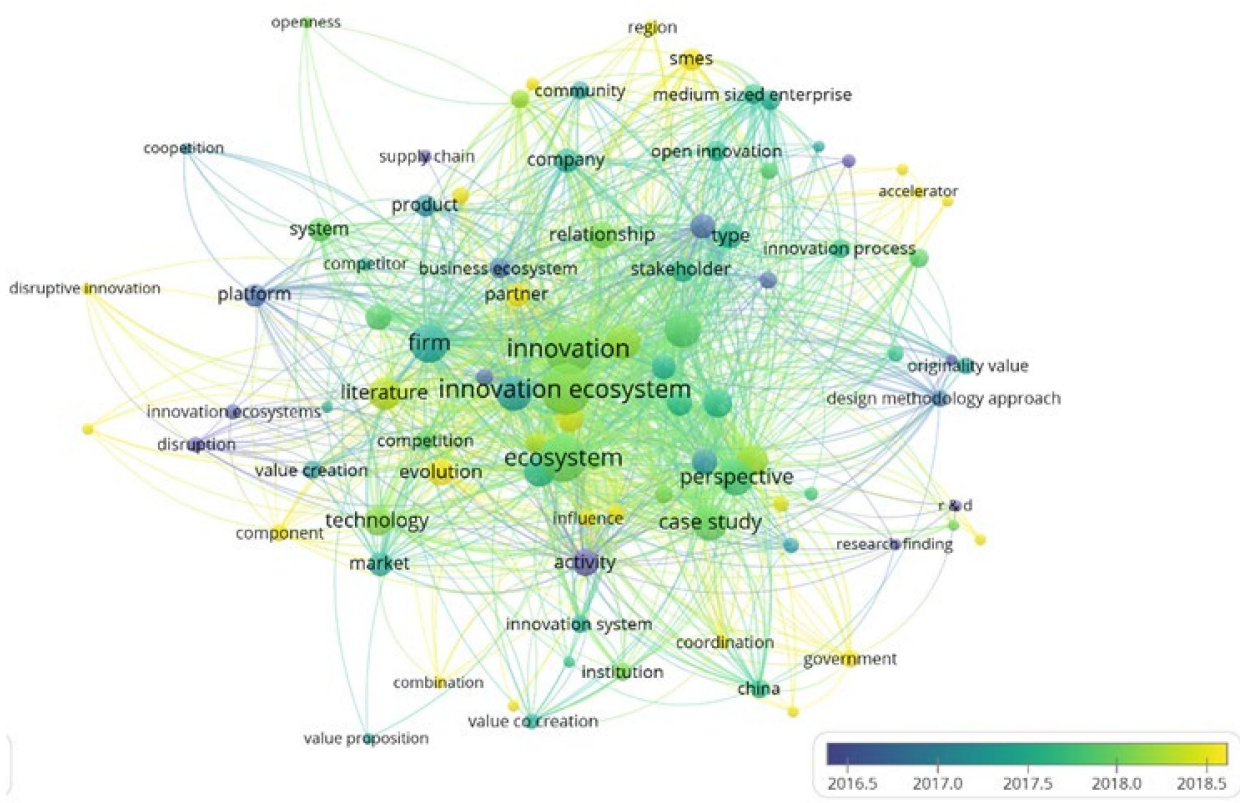

Figure 5. Keyword overlay visualization. 
Through a visual analysis of keywords, the following questions regarding the EIEs theme can be asked (the front of the symbol "-" indicates the keywords that are clustered out, and the back of the symbol "-" indicates the keywords summarized in this research; (no) indicates that the keyword does not appear in the cluster):

RQ a. How can the EIE position be clarified in the overall innovation ecosystem?

Corresponding keywords:

Innovation ecosystem-innovation ecosystem: country-NIEs, region-RIEs, industryIIEs, and firm/company-EIEs.

RQ b. What is an EIE, including its entity, type, motivation mechanism, and evolution mechanism?

Corresponding keywords:

1. (no)-entities:

(1) component-key components: actor/key actor-key actors, supply chain-innovation chain, network-innovation network, and platform-innovation platform.

(2) (no)-artifacts: technology-technology, knowledge-knowledge, and resourceresources.

(3) relationship-relations: cooperation/coopetition/collaboration/combinationcollaborative, complementarity-complementary, and competition-competitive.

2. type-types: SMEs-SMEs, (no)-core enterprise.

3. (no) motivation: driver-driving factors and barrier-hindering factors.

4. evolution-evolution.

RQ c. How is an EIE defined?

The definition of an EIE cannot be obtained through keyword cluster analysis. After clearly explaining RQa and RQb, an EIE will be systematically defined in the follow-up work to this research.

RQ d. What are the avenues for future research?

Combination of the overlay view of Figure 5 to obtain the keywords that characterize the latest research progress and future trends of EIEs.

Corresponding keywords:

ecosystem/innovation ecosystem-ecosystem, triple helix-triple helix, entrepreneurship-entrepreneurship, destructive innovation/destruction-destructive innovation, open innovation-open innovation, sustainability-sustainable innovation, value co-creation/value capture-value creation and capture.

\subsection{Data Synthesis}

The research framework of EIEs can be obtained through keyword clustering and previous scholars' research. First, since its emergence, the term "innovation ecosystem" has been used in the national or regional innovation environment. To enhance national or regional competitiveness and sustainable innovation through continuous innovation and development (such as Silicon Valley) [2]. Therefore, some scholars have proposed that the innovation ecosystem is divided into NIE, RIE, IIE, and EIE based on the construction of innovation ecosystem model and specific regional space. The keyword clustering combined with this research coincides with current scholars' classification [2,6]. This research will clarify the role and position of EIEs in the overall innovation ecosystem.

Second, a review article published on Technovation in 2020 quickly became a highly cited paper. The study pointed out a new definition of the innovation ecosystem: An innovation ecosystem is the evolving set of actors, activities, and artifacts, and the institutions and relations, including complementary and substitute relations, that are important for the innovative performance of an actor or a population of actors [2]. This study combines the composition of the innovation ecosystem proposed by the research with the keyword clustering information proposed to determine the composition of Section 3.2. To answer 
the question of what an EIE is, this research elaborates on the EIE from the perspective of its entities, types, evolution mechanism, and dynamic mechanism.

After the first two steps, the definition of the EIE comparison system is obtained. In the past, scholars have done research on the definition of an innovation ecosystem, but this research deconstructs EIEs and then reconstructs it and proposes a new definition.

Finally, keyword overlay visualization analysis can obtain the latest research progress and future research trends of EIEs as in Figure 6.

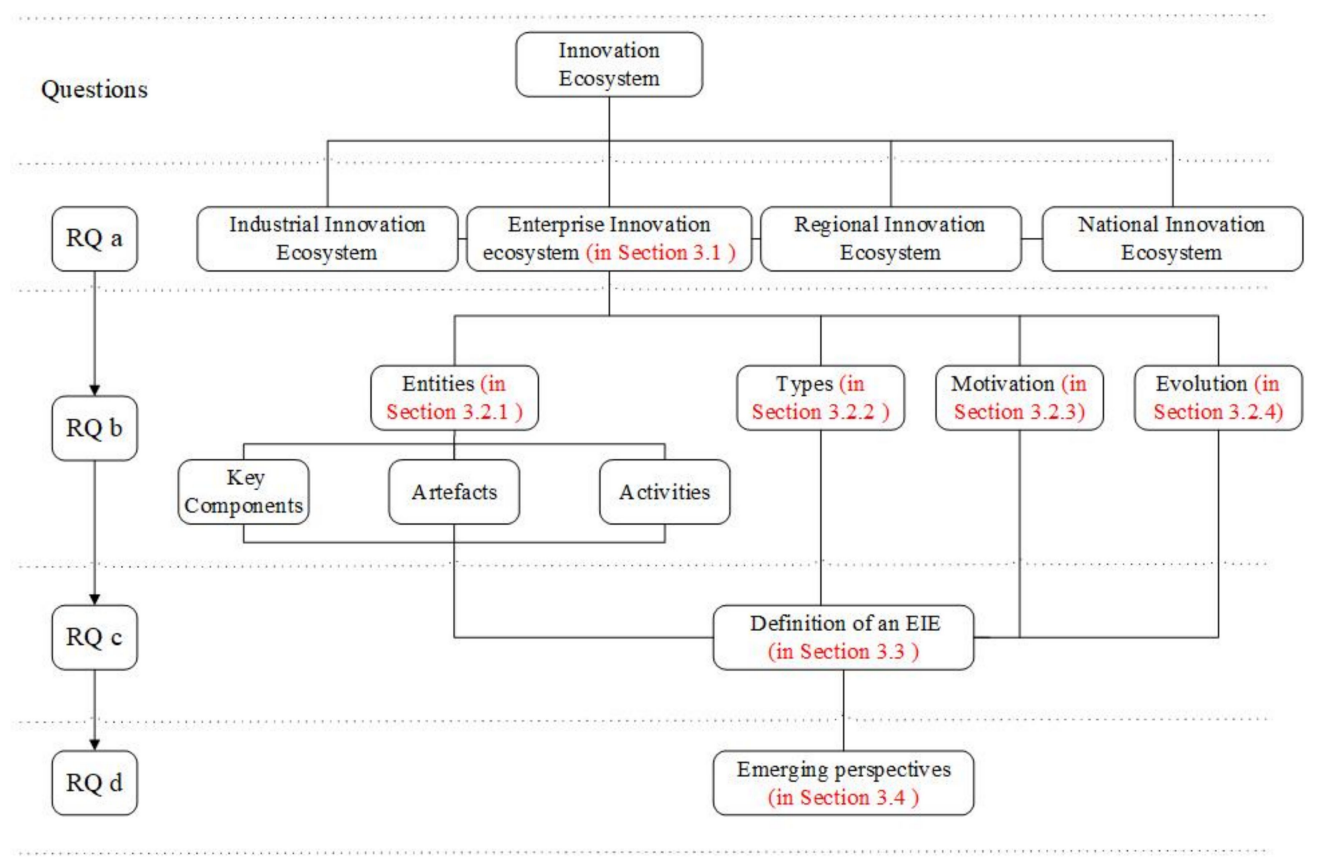

Figure 6. Research Framework.

\section{Enterprise Innovation Ecosystem Analysis}

\subsection{Clarification of Innovation Ecosystems}

According to differences in specific spatial scope, innovation ecosystems can be divided into NIEs and RIEs. While based on differences in attribute similarity, innovation ecosystems can be divided into IIEs and EIEs [2]. The concept of different types of innovation ecosystems is approximately divided into three levels and four perspectives. The three levels are, first, the macro level, which refers to NIEs; second, the medium level, including IIEs and RIEs; third, the micro-level, i.e., ecosystems centered on an innovation subject, such as enterprises, research institutes, and universities; and, most important, EIEs. The four perspectives refer to the national, regional, industrial, and corporate perspectives.

The construction of NIEs and RIEs uses administrative geographic space as an element to divide the boundaries of the overall innovation ecosystem. Generally, NIEs have abstracted away from the structure of the system, focusing on the integration of all organizations and all innovation elements in a sovereign state and its role in maintaining innovation capabilities, enhancing national competitiveness, and promoting economic development. With the development of globalization and communication technology, economic activities are manifested as spatial aggregation and localization on the one hand and as a trend of global diffusion on the other hand. The overall innovation ecosystem appears at the regional level, and through continuous innovation and entrepreneurial attempts, regional competitiveness and sustainable development are improved [2]. Wealth is concentrated in a few regions, showing regional characteristics.

The construction of industrial and corporate innovation ecosystems uses attribute similarity as an element that divides the boundaries of the overall innovation ecosystem. Like that on NIEs and RIEs, research on IIEs and EIEs has also attracted increasing attention. 
This is due to two reasons, the first of which is industrial transfer. The intensification of industrial clusters and industrial integration has led to the continuous expansion of the research space of industrial innovation ecosystems. The second reason is the constant emphasis on the entrepreneurial spirit, prompting an increasing number of people to partake in entrepreneurship and innovation, and business owners have also begun to transform from simply managing enterprises to innovative industry pioneers.

NIEs, RIEs, IIEs, and EIEs are different manifestations of the overall innovation ecosystem. The aim of exploring the interrelationship between enterprise innovation ecosystems and other innovation ecosystems is to better clarify their relationship and differences. The specific comparison of the four innovation ecosystems is shown in the following Table 3.

Table 3. Comparison Table of NIEs, RIEs, IIEs, and EIEs.

\begin{tabular}{cccc}
\hline System & NIEs & RIEs & IIEs \\
\hline Classification standard & spatial geography & spatial geography & attribute similarity \\
Level & meso & medium & medium \\
Perspective & country & region & industry \\
Aim & serve national goals & develop regional economy & development area \\
Innovation focus & national economy & regional economy & industrial development \\
enterprise & develop technology and \\
obtain resources & business growth
\end{tabular}

\subsection{Detailed and Comprehensive Analysis of EIEs}

\subsubsection{Entities of EIEs}

(1) Key components

The construction of EIEs involves the collaborative efforts of different participants in innovation. For example, suppliers provide key components and technologies, different organizations provide complementary products and services, and customers set demand and the required capabilities [10]. An EIE is a network composed of a group of participants, activities, resources, and institutions [7]. In a sense, an EIE is important for the innovation performance of one or more partner companies and other actors (such as universities, research institutes, and institutions). Figure 7 shows the components of an EIE. Enterprise innovation actors are the point that constitutes the innovation chain, and the chain constitutes the enterprise innovation network, with the innovation platform at the bottom.

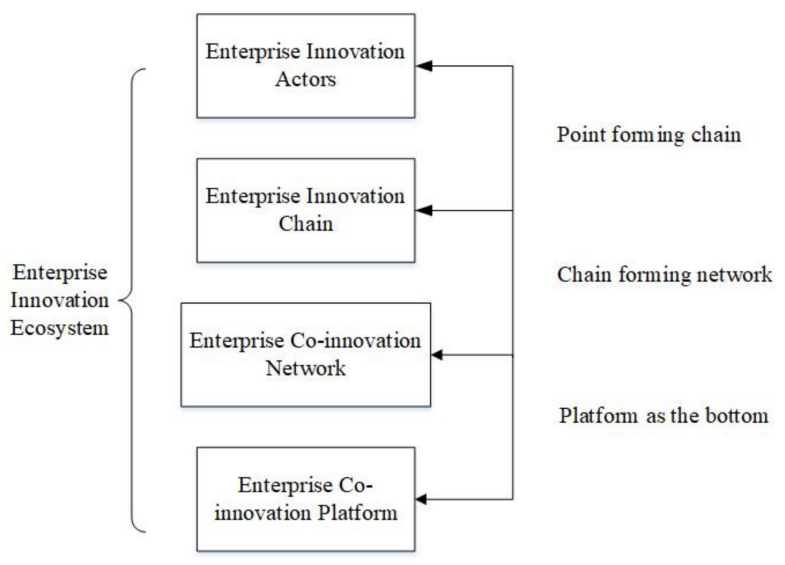

Figure 7. Components of an EIE.

(a) Point: Innovative actors

The development and evolution of an EIE is inseparable from the cooperation and coordination of a series of participants [11]. There are many participants in an innovation ecosystem, such as companies, universities, research institutions, venture capitalists, and service organizations [12]. The present research integrates the important participants that 
appear in 85 selected articles. The main participants include key companies, governments, suppliers, manufacturers, service providers, startups, small and medium-sized enterprises, etc., as shown in Table 4.

Table 4. Key actors involved in EIEs.

\begin{tabular}{|c|c|c|}
\hline Key Actors & Description & Role \\
\hline Focal firm & $\begin{array}{l}\text { Ecosystem orchestrator and provider of products and services, } \\
\text { who plays a leadership role in an innovation ecosystem }\end{array}$ & Leader \\
\hline Government & Improve policies and regulations and cultivate financing systems & Organizer \\
\hline Suppliers & Provide resources, technology, knowledge and services, etc. & Orchestrator \\
\hline Manufacturers & Product manufacturer & Participant \\
\hline Service providers & Product service provider & Participant \\
\hline Startups & Small innovative company, providing key technology & Participant \\
\hline SMEs & Small and medium-sized enterprises & Participant \\
\hline
\end{tabular}

\section{(b) Line: Innovation chain}

The formation of the enterprise innovation chain occurs simultaneously with the formation of the overall innovation ecosystem. Innovation ecology refers to the interaction between enterprises in the form of a chain. The innovation chain is based on core and sup-porting technologies. Supporting technologies include upstream and downstream complementary vertical supporting technologies and horizontal supporting technologies based on the same technological link. From the perspective of actors or technology, the innovation chain can be regarded as dynamic [13], coevolving with EIEs.

According to different types of enterprises, an enterprise innovation chain is divided into two types. The first is the horizontal innovation chain, which focuses on core enterprises, competitive enterprises, and cooperative enterprises; the second is the vertical innovation chain, which consists of core enterprises, competitive enterprises, and consumers [14,15]. There are a host of reasons for the formation of the technological innovation chain. First, the formation of the technological innovation chain stems from the limitations of the technological knowledge that enterprises have and can develop. Second, the formation of the technological innovation chain stems from the complementarity, functional diversity, and compatibility between traditional products and modern products. Finally, by joining the technological innovation chain, enterprise organizations can obtain the speed and economic effects of technological innovation, thereby gaining a competitive advantage.

(c) Surface: Co-innovation network

Innovation chains are intertwined to form an innovation network, which can be regarded as a cooperation network centered on innovation activities [5]. This innovation network includes numerous cooperative relations and innovation activities between enterprises [16]. The success of a company is not only related to its strength but also closely related to other companies within the network [17]. Thus, companies can focus on the competition and cooperation between innovation subjects. The formation of the innovation ecological network has greatly promoted industrial innovation. It can not only provide a better development environment and a good cooperation platform for innovative entities but also maintain the competitiveness of innovative entities, which will help enterprises find ways to increase value and reduce costs in the supply chain to improve the performance of the overall innovation ecosystem.

(d) Bottom: Co-innovation platform

Innovation entities share innovation resources through innovation platforms [5]. Platforms appear in multiple organizational forms: within the enterprise, across supply chains, and within industry innovation ecosystems [18]. Platform support is one strategy for reshaping EIEs [19], but it does not mean that companies can succeed in such platform support. In a complex market environment, there are conflicting forces in an ecosystem [20]. According to a large number of industry examples, innovation platforms can be 
divided into two types: internal or unique platforms and those external to the company or industry [21]. Both internal and external plat-forms have evolved with the evolution of EIEs.

\section{(2) Artifacts}

Successful EIEs are based on technical cooperation, knowledge sharing, resource coordination, encouragement of personal growth, and mutual trust among participants. Data research shows that partners form a unified trio, which includes technology, knowledge, and resources [22]. Artifacts include tangible and intangible resources, technical and nontechnical resources, and other types of system inputs and outputs, including technology and knowledge $[23,24]$.

\section{(a) Technology}

Since the mid-1990s, ecosystem research has been introduced into the field of technological innovation [25]. The input and output of EIEs are inseparable from technology. To meet customer needs, a company needs to promote technological innovation and provide valuable products and services through complementary cooperation with other companies. This complementary organization is an EIE. In a certain time and certain space, the technological-innovation-comprehensive organization and the technological-innovationcomprehensive environment interact through the flow of innovative substances, energy, and information to form an overall system, a coexisting and evolving innovation system formed by high-tech companies on a global scale with technical standards as the link and supporting technology as the foundation.

(b) Knowledge

Enterprises have limited interdisciplinary knowledge needed to independently develop complex solutions. Interdisciplinary knowledge refers to knowledge from different fields, such as production management, hardware, software, communication networks, and data management [26]. Each member of an EIE exchanges knowledge and products in the cooperation network, adapts to one another, and evolves together [27]. There are two kinds of knowledge flow: knowledge flow from outside to inside and that from inside to outside [28]. Knowledge flow from outside to inside refers to the knowledge that an enterprise brings in from the outside. When the enterprise cooperates with partners, customers, suppliers, or other stakeholders, this flow occurs when business performance is improved, reducing costs. Knowledge flow from inside to outside refers to companies seeking solutions to share knowledge, which has been obtained from other resources, to add value to the company.

(c) Resources

Many resources help companies gain a competitive advantage. The strategy of companies cooperating and competing in a cooperative business network at the same time and the heterogeneity of resources cause monopoly rent, which is a bargaining chip for profit creation [29]. To better respond to market opportunities, an EIE allows for the sharing of necessary capabilities and resources to operate products and systems on this basis [28]. Innovation resources refer to resource reserves that maintain the sustainable state of industrial innovation ecosystems. If one wants to maintain continuous innovation, the firm can achieve it through talent, capital, material, technology, and other elements. Of course, these are also guaranteeing the smooth development of system innovation activities. The impact of innovation resources on innovation activities is mainly reflected in two aspects. The first is the process of resource acquisition. When innovation resources appear, relevant innovation activities must be carried out to attract more resources into the system; second, the process of resource utilization must be considered. When innovation resources appear, rational and orderly innovation activities can introduce more cutting-edge and high-end innovation resources into the system. 
The relations in EIEs obtained by keyword clustering include collaboration, complementarity, and competition, which are consistent with those in biological ecosystems. In the development process of EIEs, the various participants of franchise platforms will inevitably revolve around resources and rely on cooperative innovation and other modes of cooperation, complementarity, and competition. However, because of the formation of cooperative, complementary, and competitive mechanisms, the relationships between participants are constantly changing, promoting the ecological development of EIEs.

The first step is to form a cooperative relationship. Many companies in EIEs focus on the concept of mutual benefit and win-win. To realize his/her interests, each participant in the system will cooperate based on cooperative research and development, technological innovation, and achievement transformation.

Second, a complementary relationship will be formed. In biological ecosystems, two organisms form a mutually beneficial symbiotic relationship. After the two are separated, they cannot live independently. In the development of EIEs, companies may also form a complementary relationship similar to the previously mentioned mutually beneficial symbiosis, build a reasonable benefit distribution mechanism between companies, and realize common development based on complementary advantages.

Third, the most important and common relationship is the competitive relationship. At each stage of an EIE evolution, there will be different degrees of competition among internal enterprises due to environmental uncertainty, resource scarcity, and other factors, which are mainly reflected in two forms: competition between core enterprises and competition between core enterprises and SMEs.

EIEs are based on a new network development platform and complementary modules and aim to give full play to the standardization of technology and indicators, as well as to form a series of cooperative and complementary competition relationships established under the new model and beyond the traditional market to increase their effectiveness. The complementary effect of the system ultimately achieves the goal of win-win symbiosis among enterprises in the system.

\subsubsection{Types of EIEs}

According to the method of the European Commission and the European Innovation Scoreboard, the enterprise dimension is divided into small, medium, and large enterprises [30]. There are two types of EIEs: one type has an obvious core enterprise (large enterprise), where there is a leader in the innovation ecosystem. The other type has no obvious core enterprise, and there is no leader.

(a) EIEs without a core enterprise(s)

There is no innovation leader in the entire system. The enterprises in the system are mainly small- and medium-sized enterprises, and each SME spontaneously seeks and establishes external innovation cooperation relationships as in Figure 8.

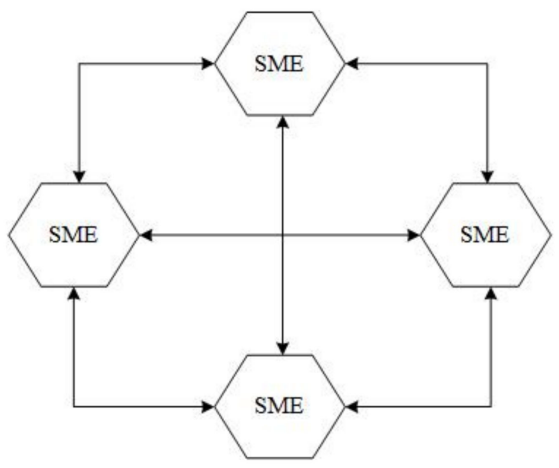

Figure 8. EIEs without core enterprise. 
Ubreziova et al. surveyed 150 SMEs in the Republic of Moldova, utilizing questionnaire surveys, and concluded that a weak EIE slows the development of enterprises and that the economic performance of SMEs directly affects the national budget [31]. Therefore, it is extremely important to build a strong SME innovation ecosystem. Kahle et al. researched a case of an electronics and automation industry cluster composed of 120 SMEs and other auxiliary participants (such as governments and universities). Moreover, pointed out that the development of smart products requires knowledge and capabilities, but a single company does not usually have such knowledge and capabilities. In the innovation ecosystem of smart products, SMEs aim to create new cooperation opportunities and establish partnerships [32]. Reynolds et al. paid special attention to SMEs and explored the ways and opportunities for Massachusetts manufacturers to establish and cultivate innovation capabilities. Manufacturers, SME suppliers, startups, and universities/research institutions play a role in national advanced manufacturing innovation ecosystems [33]. SMEs seek cooperation in competition, forming an EIE without leaders.

(b) EIEs with a core enterprise(s)

This type of EIE has one or several large enterprises of the same type with monopolistic capabilities. Both core companies and noncore companies need to coordinate systems and services. This coordination is based on structure control [34,35], which will help with value sharing and value creation and promote overall development [25]. The definition of a core enterprise is still ambiguous and controversial in the existing literature, and the term is often used interchangeably with the concepts of a central enterprise, flagship enterprise, leading enterprise, and focal enterprise [2]. Although the definition of a core enterprise cannot be determined, there is no doubt that the core enterprise is the most critical innovation entity in an EIE as in Figure 9.

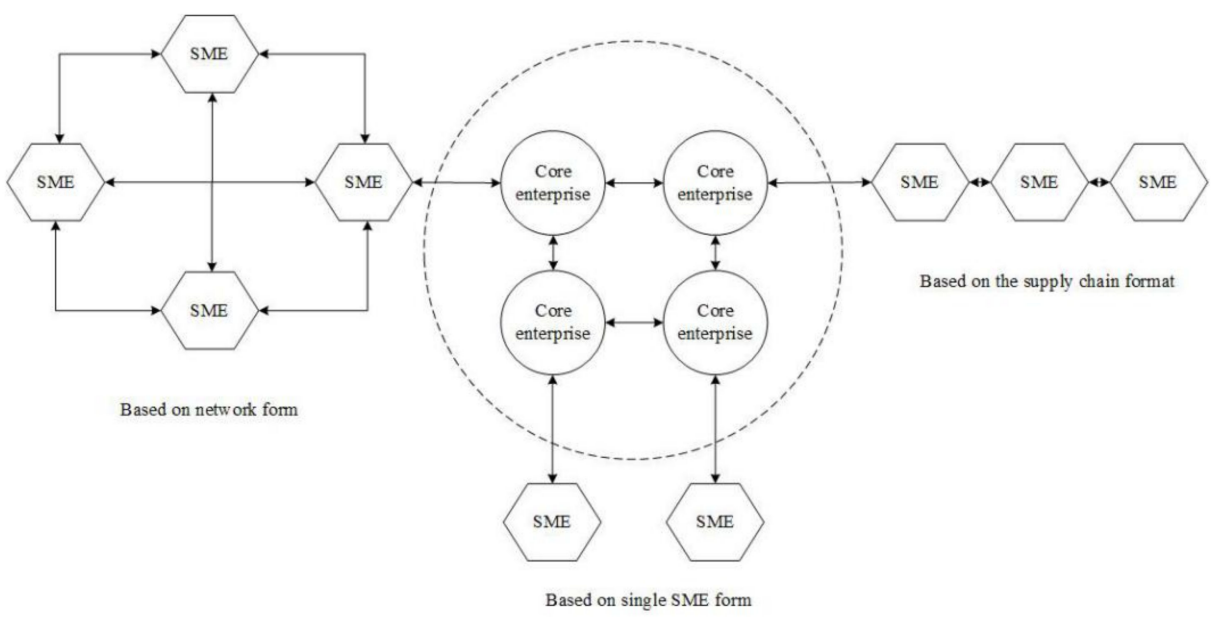

Figure 9. EIEs with (a) core enterprise(s).

Core enterprises are located at the center of innovation ecosystems and provide a way to communicate with various participants. Core enterprises have established a platform for partnerships to promote knowledge flow, accelerate the innovation process, promote value realization, and finally launch new products or services [2]. A hub-based innovation ecosystem, with core companies as ecosystem leaders, can set goals and define innovation platforms, which will have a significant impact on the strategy and destiny of all other members [20]. The results show that the establishment of an ecosystem with core companies as leaders can improve the innovation motivation and innovation efficiency of enterprises [27]. Corresponding examples can be seen in many industry benchmark companies, such as Pfizer's biotechnology ecosystem, IBM's power architecture ecosystem, Intel's microprocessor ecosystem, and Apple's iPhone ecosystem [20]. EIEs with leaders are increasingly becoming a trend, and the establishment of EIEs by advanced international companies indicates the development of SMEs. 


\subsubsection{The Motivating Mechanism of EIEs}

Innovation motivation mainly refers to the various sources of factors that can promote the creation of the innovation needs of innovation subjects. The research on innovation power began by focusing on the earliest single-factor influence and then gradually developed into a focus on multiple angles and multiple factors. According to the nature of the main factors affecting the development of EIEs, they can be divided into three driving modes: extrapolation, hybrid, and internal [36]. The pressures stemming from the market, resources, and technological environment have become the main external driving factors for the government in promoting industrial development, and enterprises build enterprise innovation ecosystems based on these external driving factors [37,38]. The internal interaction of profit-driven strategic synergy, innovation, and evolution promotes the construction of EIEs [27]. Based on the keyword analysis in previous research, this paper deconstructs the internal and external power of the power elements into driving and hindering forces.

The construction and development of EIEs are realized under the combined influence and action of multiple dynamics, including impetus and hindrance. Specifically, driving forces include internal interest motivations, technological driving forces, policy guidance forces, and industrial resource forces. Under the combined action of these driving forces, the upgrading and evolution of EIEs can be effectively promoted; obstacles to such promotion include the technological motivation deflection angle and technology flow resistance and environmental resistance, and these obstacles will hinder the construction and development of EIEs.

\section{(1) Driving forces:}

\section{a. Innovation benefits}

The most important driving force for EIE development is profit, which is an internal driving force. Any company aims to pursue profit; therefore, a company's creation of an innovation ecosystem is driven by profit.

\section{b. echnology promotion and technological gap}

Technology promotion and technological gaps are the cohesive power and important driving force of EIEs and important motivations for the main innovation body to construct EIEs. The development of science and technology provides a platform for enterprise innovation activities. In EIEs, the development of science and technology not only promotes innovation entities to carry out innovation activities but also accumulates scientific and technological research for the core enterprises in ecosystems.

\section{c. Policy guidance}

When an enterprise loses its advantage in the market, it needs external guidance. At this time, policies play a supporting role. Under the guidance of relevant policies, this study analyses the characteristics, changes, and behaviors of innovative activities from the EIE perspective. To give full play to the role of enterprises in promoting innovation, accelerating the innovation process, and reducing costs and risks, the government needs to implement new macro-control policies that are conducive to communication and cooperation between innovative entities. The main policies include innovation and industrial policies, so such policies guide one of the innovation drivers of EIE operation.

\section{d. Industrial resources}

Innovation resources are the basic conditions for any system to carry out innovative activities. Funds, talent, and information are the basic guarantees for innovation in industrial innovation ecosystems. Universities and scientific research institutions can provide enterprises with a large amount of relevant professional talent to promote the sustainable development of industrial innovation eco-systems. At the same time, the cooperation model of industry, university, and research promotes the exchange of talent, especially the internal information exchange of the system as well as the internal and external exchanges. Such exchange has greatly increased the enthusiasm of innovative entities in carrying out innovative activities within the system. Therefore, the effective allocation of innovation 
resources in industrial innovation ecosystems ensures the continuous development of innovation activities.

(2) Hindering forces:

\section{a. Technology resistance}

Technology is a double-edged sword for the formation and development of EIEs, as it can promote the construction of EIEs and also can become a hindrance. The lack of technical support, the decline in technical power, and the obstruction of technology flow are the main obstacles that limit the growth and expansion of EIEs.

\section{b. Environmental resistance}

The environment mainly refers to the external innovation environment of EIEs. For example, the "excessive pressure" of the external innovation environment of EIEs will lead to the innovation information, materials, and knowledge in the system to overflow from innovation channels to surrounding areas. Therefore, EIEs must establish strong internal environments for innovation, break their dependence on paths, and ensure the prosperity of their innovation. At the same time, industrialized environmental pollution has also become an obstacle to the development of EIE symbiosis and symbiosis theory.

\subsubsection{The Evolution of EIEs}

At present, most scholars' research on the evolution of EIEs is static rather than dynamic [25]. The development and evolution of EIEs is a nonlinear and complex dynamic process [27]. At present, EIEs include three main innovation evolution models, namely the one-way linear innovation model, the interactive innovation model, and the modern nonlinear innovation model. The innovation ecosystem has a life cycle and follows a co-evolution process [25]. The construction of EIEs was chaotic at the beginning. Later, due to the needs of innovation and development, EIEs brought together resources, technology, knowledge, and customer needs and experienced the formation [39], incubation [40], and development of the overall innovation ecosystem, renewal [19], or death.

EIEs go through four stages: birth, expansion, leadership, and self-renewal or death [26]. The first stage is the birth stage of EIEs. Participants focus on value proposition and seek cooperation. The second stage is the expansion stage of EIEs, where companies begin to expand when they gain competitive advantages. The third stage is to become a leader. The core enterprise governs the innovation ecosystem and expands the scope of control by shaping the future development direction and investment of key customers and suppliers. The last stage is the self-renewal or death of EIEs. When the ecosystem is threatened, self-renewal or death will occur as in Figure 10.

Initially, when the ecological level was at a low level, EIEs were widespread. The symbiotic evolution of innovative ecosystems obeys the laws of biology. There is a symbiotic relationship that is both competitive and synergistic between ecosystems. This symbiotic relationship comprises the driving factors that promote the original ecosystem to advance to a higher level of ecology. With the improvement of the ecological level and the positive traction of power elements, EIEs have gradually become comprehensive and intelligent. In the birth stage and expansion period of EIEs, the number of individual participants in the innovation ecosystem is small, and the symbiosis environment is superior. It is a stage of gaining momentum; the ecological level of the ecosystem is low at this time. In the leadership and self-renewal stages of EIEs, the number of participants has gradually increased, the environmental capacity has tightened, and demand and supply have reached a balance. At this time, the ecological level of the ecosystem is higher. 


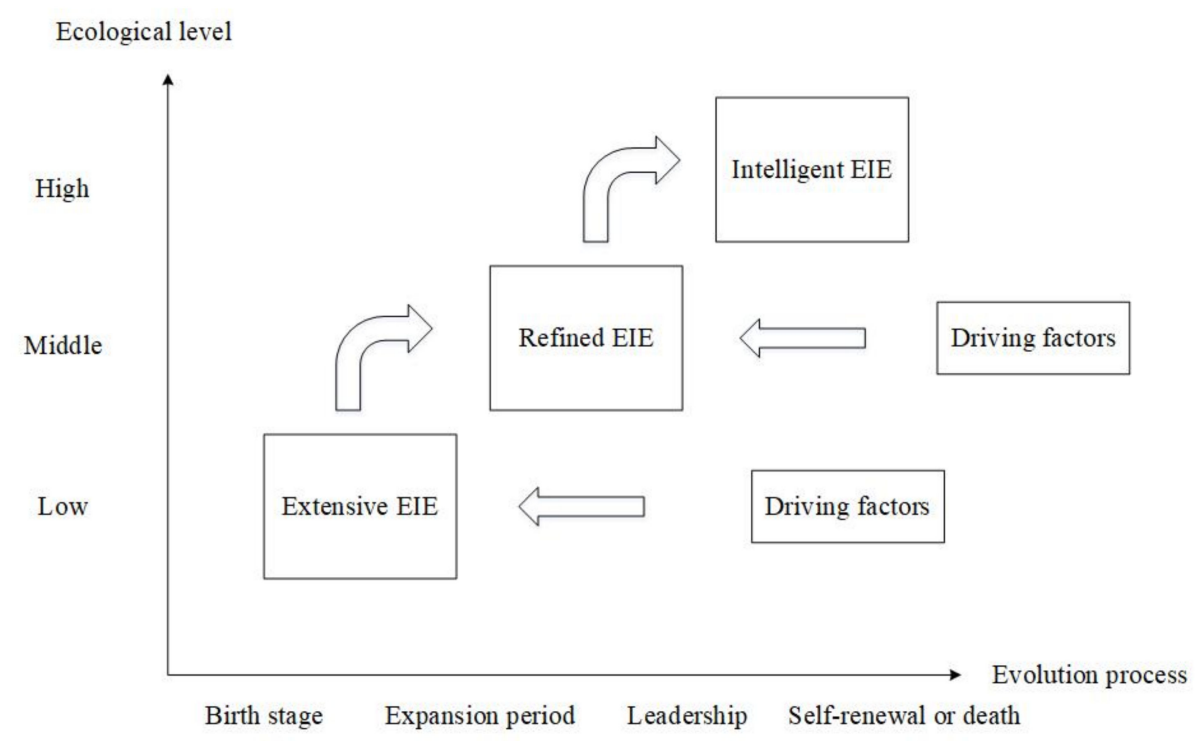

Figure 10. Evolution of EIEs.

\subsection{Definition of EIES}

After clarifying the entity composition, main types, dynamic mechanism, and evolution mechanism of EIEs, this research further explores the definition of EIEs, which has been the focus of many scholars' research. This article combs the definition of the representative concepts of EIEs from different perspectives.

Adner and Kapoor believe that an EIE has an interdependent structure, which is composed of key companies as the core, upstream components bundled by key companies, and downstream supplementary components bundled by company customers [41]. Their study pointed out one type of EIEs, that is, an innovation ecosystem led by core companies, and pointed out that EIEs are a chain structure composed of upstream and downstream components. Ritala believes that an EIE is a leading company for promoting value creation and acquisition, forming a tangible and intangible mechanism, attracting and gathering relevant stakeholders, and maintaining and achieving the business goals of all ecosystem participants [42]. Their research also pointed out that EIEs are large enterprises that build an innovation ecosystem with themselves as the core, attracting many participants to join, with the purpose of achieving value capture and then achieving business goals. Granstrand and Holgersson defined an innovation ecosystem as follows: an innovation ecosystem is the evolving set of actors, activities, and artifacts and institutions and relations, including complementary and substitute relations, that are important for the innovative performance of an actor or a population of actors [6]. Part of the composition of this research in Section 3.2 is based on their research. Their research provides a conceptual review of the innovation ecosystem and proposes a new definition.

As a branch of the innovation ecosystem, an EIE has many similarities with the definition of the overall innovation ecosystem. Based on the above clarification of the position of EIEs in innovation ecosystems, the definition of an EIE can be systematically derived. Based on a comprehensive analysis of existing perspectives, this paper concludes that the definition of an EIE is as follows: An EIE refers to the collection of various key components, artifacts, and activities. It establishes a cooperative and competitive relationship with core enterprises or other organizations. There are external forces and resistances to meet market demand and obtain benefits, thus forming an open, dynamic and co-evolutionary, interdependent, and coexisting network system.

\subsection{Emerging Research Directions}

This research combines an analysis of cutting-edge keywords and a summary of opinions from 85 articles, resulting in the following seven emerging perspectives, which 
are all hot spots. The emerging perspectives on EIEs are mainly developed from the perspectives of ecosystems, the triple helix, entrepreneurship, disruptive innovation, open innovation, sustainable innovation, value creation, and value capture.

\section{a. Ecosystem perspective}

Scholars who study EIEs analyze them from the perspective of ecosystems. (a) Role perspective: Dedehayir et al. explored the role of EIEs through a literature review. According to their theme, the roles of EIEs are divided into four categories: leadership role, direct value-creation decision-making role, value-creation support role, and innovation ecosystem role [10]. (b) Method perspective: Stenroos and Ritala reviewed the specific characteristics of the ecosystem approach and identified four categories: competition and evolution, emergence and interruption, stable commercial exchange, and co-creation value [43]. (c) Dynamic control perspective: Dattée proposed that the creation of an ecosystem is a systematic process driven by a coupled feedback loop and that organizations must strive to dynamically control this ecosystem [44]. Enterprises with high service innovation intensity have stronger ecological-related capabilities than do those with low service innovation intensity [11]. (d) Suggestions for companies: Ubreziova et al. conducted research on 150 small and medium-sized enterprises in the Republic of Moldova, pointed out that a weak innovation ecosystem and lack of high-quality workers slowed down the development of enterprises, and put forward several suggestions for business managers and high-level government organizations [31]. (e) Ecological stage perspective: based on an exploratory case study on the innovation eco-system of China's high-speed railway industry, some authors have identified three ecosystem stages, namely the technology accumulation period, the technology introduction period, and the independent innovation period [25].

b. Triple/Quadruple/Quintuple helix

In EIEs, the participants of the triple helix have common goals, have common views on standards and quality, and can cooperate in a more comprehensive manner [45]. Arenal et al. summarized the construction of China's artificial intelligence innovation ecosystem, which is the key feature of the three fields of the triple helix (the government, industry, and academic/research institutions) and summarized the dynamic background of this ecosystem [17]. Pique et al. determined the changes in the role played by triple-helix agents, using startup companies as the analysis unit and multi-case research methods and based on the results of triple-helix analysis to understand the evolution of Silicon Valley's innovation ecosystem [46]. Carayannis et al. and Feng et al. proposed an "ecosystem" approach that can provide an integrated framework for social business models that can enhance the existence of quadruple and quintuple helix [47,48]. Costal et al. point toward the importance of the user community and the environment in the promotion of dynamic ecosystems. Both the triple/quadruple/quintuple helix and innovation ecosystems are theories. When the two are combined, they can collide [49].

\section{c. Entrepreneurship}

Entrepreneurship is very valuable in the prevailing commercialization environment of developing economies. It refers to the ability to use resources and specifically solve corporate problems. Nambisan and Baron focused on the self-regulation processes of ecosystem entrepreneurs and the potential role of these processes in entrepreneurs' efforts to successfully balance the requirements set forth by ecosystem leaders and their own corporate goals [20]. Surie studied how social entrepreneurship promotes innovation and economic development at the financial and institutional levels [50]. Therefore, a good study of the theme of entrepreneurship helps companies build EIEs.

\section{d. Destructive innovation}

Ahmad Beltagui investigated disruptive innovation by exploring the relationship between two ecological concepts, evolution and ecosystems [51]. Maximilian Palmié 
focused on the impact of ecosystem development and evolution on disruptive innovation, defined disruptive innovation ecosystems, and illustrated the impact of financial technology ecosystems on the destruction of financial services [52]. Bob Walrave clearly considered the sociotechnical feasibility of innovation ecosystems in destructive innovation and contributed to the literature on innovation ecosystems [53]. By resetting the relationship between participants in innovation ecosystems, disruptive innovation will affect the entirety of these innovation ecosystems [54]. This research claims that it will add more value distinguishing between Schumpeter M1 and M2.

\section{e. Open innovation}

In view of the importance of collaborative efforts among multiple stakeholders, Radziwon addressed the challenges of open innovation at the business ecosystem level from the perspective of SMEs [55]. Chesbrough et al. used the Chez Panis ecosystem case study to analyze how Chez Panis grew up using open innovation [56]. The above scholars and their team used an "open innovation" strategy to interact with suppliers, alumni chefs, employees, and food writers. Together with stakeholders, a local and current global ecosystem was established [57-60].

\section{f. Sustainable innovation}

Klewitz and Hansen closed the EIE research gap by proposing radical special-purpose enterprises, simplified innovation methods, and the role of small and medium-sized enterprises in industrial transformation and sustainable supply chain [61]. Pucci et al. took China Aerospace Science and Technology Co., Ltd. as an example to study the management of innovation paradoxes by core enterprises in sustainable innovation ecosystems [62]. Modularization can create value with fewer resources and at lower costs, thereby achieving sustained economic innovation [63-68].

g. Value creation and value capture

Valkokari pointed out that enterprise innovation ecosystems are structures that support the co-creation of multirole value in actual innovation ecosystems [69]. Ritala focused their research on the value creation and value capture of corporate innovation ecosystems and explored how leading companies can promote value creation and acquisition-related tangible and intangible mechanisms [42]. The development of corporate innovation ecosystems mainly relies on value acquisition. The value creation process is achieved by common goals and financial support, but companies need to balance their core activities and commitment to joint plans [36]. Mantovani and Ruiz-Aliseda pointed out that in a saturated market, companies fall into a prisoner's dilemma: greater investment creates more value, but this does not translate into greater value acquisition because the value created by competitors does not change [70]. The similarities and differences between business and innovation ecosystems include that the former focuses more on value acquisition, while the latter focuses more on value co-creation [8].

These trends have prompted us to propose further research opportunities to consolidate the concepts of EIEs.

\section{Discussion}

Regarding the concept of innovation ecosystems, some scholars have used related terms vaguely and constructed related concepts conveniently according to their own research purposes [71]. As with the formation of any systematic approach, this makes it very difficult to construct the conceptual knowledge body and boundaries of innovation ecosystems [8]. Based on the fact that the definition of an innovation ecosystem has been unclear, a review article in Technovation reviewed the definitions of concepts related to innovation ecosystems and proposed a comprehensive definition of these ecosystems [6]. This concept adds competition, substitution, and artificial products to the previous concepts and builds new correspondence with the biological ecosystem.

EIEs have received increasing attention from scholars, entrepreneurs, and policy makers [10]. In the latest research, Chen et al. concluded that the innovation ecosystem can 
enable small and medium-sized AI companies to grow. Moreover, they pointed out that an excellent ecosystem needs to establish a mechanism. This mechanism can help companies not only select partners, reduce cooperation costs, but also strengthen the protection of intellectual property rights [72]. According to the evolution stage of the enterprise and the ecosystem in which it is located, Nylund et al. drew a conceptual model of the role of multinational corporations in order to maintain the sustainable innovation of the enterprise [73]. Zheng et al. explored the structure, evolution mechanism, and path characteristics of EIEs through corporate cases [74]. It can be seen that scholars still use cases to analyze and explore EIEs, study their structure, evolution, mechanism, etc., in order to maintain the sustainability and innovation vitality of enterprises. Research conclusions can not only enrich and develop EIEs' theory, but also provide enlightenment for EIEs' strategic transformation. This study chose a classification of EIEs in innovation ecosystems for analysis and deconstruction because the definition of an EIE is currently unclear. A basic question is what the relationship between EIEs and innovation ecosystems is, how it is constituted, and its definition. Previous research has focused on the composition, type, dynamic mechanism, and evolution mechanism of EIEs. However, such research has been conducted separately, and each focus has been studied. Unlike previous studies, this article attempts to provide a relatively comprehensive framework for entity composition, type, dynamic mechanism, and evolution mechanism, rather than focusing only on specific aspects of EIE-related components and elements. The research results of this article have positive enlightenment significance for the practice of enterprises. Enterprises are clear about their position in EIEs, whether they are leaders or being led. When implementing ecological strategies, enterprises need to extensively cooperate with heterogeneous entities and practice resource, knowledge, and technology interactions and long-term strategies. The construction of relationships is particularly important for improving the financial performance of a company. Second, companies need to seize the driving factors, avoid obstacles, and adjust their strategies in accordance with the EIE evolution direction. Third, under the interactions of disruptive innovation, open innovation, and continuous innovation, the selection of partners and the use of ecological flow can be dynamically focused, thereby improving corporate management performance and financial performance and achieving value creation and value capture.

\section{Conclusions}

\subsection{Conclusions}

EIEs show the prospects of the innovation chain, network, and industry platform management. This paper took the selected 85 documents as the object of analysis and conducted a systematic and comprehensive study based on the definition of an EIE and its hot spots. We draw the following conclusions: (a) Scholars' research on EIEs has entered a stage of rapid development and focuses on qualitative research. Scholars who follow the development of EIEs can focus on three journals and nine papers. (b) EIEs are presentations of the micro-level and corporate perspective of innovation ecosystems. (c) The entities of EIEs include key components, artifacts, and relationships. EIEs are divided into two types: those with a leader and those with no leader. The dynamic mechanism of EIEs is divided into a positive driving force and a negative hindering force. The evolution of EIEs is divided into four stages: birth, expansion, leadership, and renewal or death. (d) The definition of an EIE is as follows: an EIE refers to the collection of various key components, artifacts, and activities. It establishes a cooperative and competitive relationship with core enterprises or other organizations. There are external forces and resistances to meet market demand and obtain benefits, thus forming an open, dynamic and co-evolutionary, interdependent, and coexisting network system. (e) Scholars who want to study this field can pay attention to the following seven emerging hot spots: ecosystems, triple helix, entrepreneurship, disruptive innovation, open innovation, sustainable innovation, value creation, and value capture. 
Overall, this research provides a systematic definition for the literature; that is, it provides a systematic definition for the increasingly useful but still budding consistency of fuzzy EIEs and analyses and sorts out the research hot spots of EIEs, filling the research gaps in terms of EIEs.

\subsection{Implications}

\section{a. Theoretical implications}

Innovation ecosystems are a research hot spot in the area of innovation management. As a branch of innovation ecosystems, EIEs are of great significance for clarifying their definition and development. The research framework and main conclusions of this article make a positive theoretical contribution to the field. First, this article summarizes the previous research work and scattered knowledge in the field of EIEs to provide a relatively complete analysis framework for the study of EIEs. Based on the analogy of biology and innovation ecosystems, entities, types, dynamic mechanisms, and evolutionary mechanisms are the core elements of EIEs. This article's analysis of the four core elements of EIEs will help reveal the composition of EIEs. Second, this research helps further identify and distinguish among NIEs, RIEs, IIEs, and EIEs and briefly clarifies the relationship between EIEs and innovation ecosystems. By clarifying the relationship and comprehensive viewpoints, combined with the definitions provided by other scholars, a clear and systematic definition of an EIE is presented. Finally, this research explores the emerging hot spots of this subject, which enables scholars who wish to enter the field to explore the trend of the subject as soon as possible. This is a breakthrough that has further enriched EIE theoretical research from the perspective of the system as a whole.

\section{b. Practical implications}

An increasing number of firms are beginning to implement ecological strategies, with the aim of improving corporate performance and gaining long-term competitive advantages by constructing EIEs. The research results of this article provide positive insight into the practice of enterprises and can provide a reference for practitioners to choose innovative strategies according to their roles. Large companies are usually the leaders of EIEs. A core company is not a predator that threatens other companies in an ecosystem. Good competition, cooperation, and symbiotic relationships help the entire ecosystem achieve a dynamic balance, thereby promoting the sustainable development of an EIE. Based on the relationship of mutual trust, core companies and SMEs cooperate. Of course, core enterprises should design an ecosystem value proposition to attract more key players to participate in the ecosystem and share the supplementary resources, technology, and knowledge needed for innovation. In the long run, the success of EIEs depends on sustainable value creation and value capture. Small and medium-sized enterprises, on the one hand, can choose to participate in the existing strategic partnerships of small and medium-sized enterprises that match their capabilities and resources. On the other hand, they can establish cooperative partnerships with each other to build an innovation ecosystem with sustainable and intelligent components. When the value appropriability of individual actors is guaranteed, EIEs can balance the tension between competition and cooperation.

\section{c. Policy recommendations}

In most cases, the current policy package still depends on closed innovation paradigms, focusing on protecting state companies and subsidizing larger organizations [71]. The government plays an important role in the evolution of EIEs. Since it is a decision-maker and financial supporter affecting innovation, its implementation of relevant policies must improve the efficiency of the innovation ecosystem and maintain a sound and orderly development of the innovation ecosystem. First of all, the government should transform the technological policy of industrial structure development into an innovation policy based on ecological concepts in order to build a more open and sustainable innovation ecosystem. Secondly, the construction of the innovation ecosystem has gradually attracted the attention 
of the state, government, industries, and enterprises. The state and government should pay attention to the development of the innovation ecosystem, promulgate relevant policies to implement innovation ecosystem evaluation, and ensure the sound evolution of the innovation ecosystem. Finally, the new innovation policy must not only maintain the leadership position of core companies, but also consider the role of technology, knowledge, and resources in promoting small and medium-sized enterprises.

\subsection{Research Limitations and Future Research}

Firstly, this article aims to conduct a systematic review of EIEs and discuss the key points and hot spots of the literature from the past decade. Although it is sufficiently systematic and as comprehensive as possible, there are still some limitations. First, this study only covers one database - Web of Science - and other database studies published in EIE-related literature were not included. The Web of Science database was carefully selected, as it provides a comprehensive description of EIEs in this field. The inclusion of other databases may not fundamentally change this. However, to be more comprehensive and credible, future research can collect and organize relevant documents in all databases. Secondly, this research needs a more rigorous conceptual framework description. Although this framework is based on the keyword clustering of all target documents and refers to some classic documents, which can reflect the literature perspectives of EIEs to a certain extent, it lacks a structured method for evaluating its logic; thus, future research can improve and verify the theoretical framework. Finally, the conceptual framework needs to be verified in more case studies to ensure its applicability [36]. For example, from the perspective of modularity, Zhang et al. explored the structure, evolution mechanism, and path characteristics of the EIE through the longitudinal case of the Haier Group [55]. Future research should use experience to prove various innovation cases, including those of NIEs, RIEs, and IIEs. In summary, despite these limitations, we believe that this study provides researchers and managers with a better understanding of the rapidly expanding topic of EIEs.

Author Contributions: Conceptualization, L.F. and J.L.; methodology, L.F.; software, J.L.; writingoriginal draft preparation, J.L.; writing—review and editing, J.W.; visualization, J.L.; supervision, L.F.; project administration, J.W.; funding acquisition, J.W. All authors have read and agreed to the published version of the manuscript.

Funding: This research was funded by the Innovation Method Fund of China with grant number 2018IM020300, 2019IM020200; and Shanghai Science and Technology Program (Project No. 20040501300).

Institutional Review Board Statement: Not applicable.

Informed Consent Statement: Not applicable.

Conflicts of Interest: The authors declare that there is no conflict of interest regarding the publication of this paper. 


\section{Appendix A}

Table A1. Purpose of the study, research design, and key findings of highly cited literature.

\begin{tabular}{|c|c|c|c|c|}
\hline Serial Number & Title of Top Cited Articles & Purpose of the Study & Research Design & Key Findings \\
\hline 1 & $\begin{array}{l}\text { Connecting local entrepreneurial } \\
\text { ecosystems to global innovation } \\
\text { networks: open innovation, double } \\
\text { networks and knowledge integration }\end{array}$ & $\begin{array}{l}\text { The research explores whether R\&D } \\
\text { strategies such as open innovation, } \\
\text { knowledge integration, and double } \\
\text { networks will be affected by the } \\
\text { innovation ecology. }\end{array}$ & Qualitative Research Design & $\begin{array}{l}\text { This study suggests a simultaneous need for } \\
\text { local and global, as well as internal and } \\
\text { external, knowledge integration. }\end{array}$ \\
\hline 2 & $\begin{array}{l}\text { Entrepreneurship in Innovation } \\
\text { Ecosystems: Entrepreneurs' } \\
\text { Self-Regulatory Processes and Their } \\
\text { Implications for New Venture Success }\end{array}$ & $\begin{array}{l}\text { The research focuses on the } \\
\text { self-regulating processes of ecosystem } \\
\text { entrepreneurs and the potential role of } \\
\text { these processes in entrepreneurs' efforts } \\
\text { to balance the requirements set by } \\
\text { ecosystem leaders with their own } \\
\text { corporate goals. }\end{array}$ & $\begin{array}{l}\text { Qualitative Research Design: the } \\
\text { focus is on the hub-based innovation } \\
\text { ecosystem, which involves a single } \\
\text { company in which a company } \\
\text { assumes the leadership of the } \\
\text { ecosystem }\end{array}$ & $\begin{array}{l}\text { Promote the understanding of the innovation } \\
\text { ecosystem by arousing attention to the } \\
\text { potential role of all aspects of the } \\
\text { entrepreneur's self-regulation process on the } \\
\text { success of the innovation ecosystem. }\end{array}$ \\
\hline 3 & $\begin{array}{l}\text { Industry Platforms and Ecosystem } \\
\text { Innovation }\end{array}$ & $\begin{array}{l}\text { The research brings together the latest } \\
\text { literature on "industry platforms" and } \\
\text { shows how it relates to managing } \\
\text { innovations inside and outside the } \\
\text { company, how to deal with technological } \\
\text { and market interference, and changes } \\
\text { over time. }\end{array}$ & $\begin{array}{l}\text { Qualitative Research Design: } \\
\text { literature analysis and case } \\
\text { comparison analysis }\end{array}$ & $\begin{array}{l}\text { First, analyze the examples of different } \\
\text { industries and divide the platform into } \\
\text { internal platforms and external platforms; } \\
\text { secondly, summarize the general propositions } \\
\text { about platform design, economics, and } \\
\text { strategic management; finally, review Intel's } \\
\text { case and other examples to illustrate the } \\
\text { technical, strategic and business challenges } \\
\text { faced by platform leaders and their } \\
\text { competitors. }\end{array}$ \\
\hline 4 & $\begin{array}{l}\text { Innovation through } \\
\text { Institutionalization: A Service } \\
\text { Ecosystems Perspective }\end{array}$ & $\begin{array}{l}\text { This article explores the role of } \\
\text { institutions in innovation from a } \\
\text { service-ecosystems perspective, which } \\
\text { helps to unify diverging views on } \\
\text { innovation and extend the research } \\
\text { regarding innovation systems. }\end{array}$ & $\begin{array}{l}\text { Drawing on institutional theories, this } \\
\text { approach broadens the scope of } \\
\text { innovation beyond the firm. }\end{array}$ & $\begin{array}{l}\text { Market innovation is driven by the } \\
\text { combinatorial evolution of value propositions } \\
\text { and the emergence and } \\
\text { institutionalization of new solutions. }\end{array}$ \\
\hline
\end{tabular}


Table A1. Cont.

\begin{tabular}{|c|c|c|c|c|}
\hline Serial Number & Title of Top Cited Articles & Purpose of the Study & Research Design & Key Findings \\
\hline 5 & $\begin{array}{c}\text { Innovation Ecosystems: A Critical } \\
\text { Examination }\end{array}$ & $\begin{array}{c}\text { This paper is a critical review of the } \\
\text { "innovation ecosystem" } \\
\text { idea. }\end{array}$ & $\begin{array}{l}\text { Literature review, logical } \\
\text { argumentation, and examination of } \\
\text { national projects }\end{array}$ & $\begin{array}{l}\text { This study describes the gaps in the } \\
\text { innovation ecosystem, points out the } \\
\text { direction to close the gaps, and provides } \\
\text { recommendations for the careful use of the } \\
\text { term "ecosystem". }\end{array}$ \\
\hline 6 & $\begin{array}{c}\text { Ecosystem as Structure: An } \\
\text { Actionable Construct for Strategy }\end{array}$ & $\begin{array}{l}\text { Develop a feasible strategic framework } \\
\text { for the structure of the ecosystem }\end{array}$ & $\begin{array}{l}\text { This article presents a structuralist } \\
\text { approach to conceptualizing the } \\
\text { ecosystem construct. }\end{array}$ & $\begin{array}{l}\text { The study presents a clear definition of the } \\
\text { ecosystem construct, a grammar for } \\
\text { characterizing ecosystem structure, and a } \\
\text { characterization of the distinctive aspects of } \\
\text { ecosystem strategy. }\end{array}$ \\
\hline 7 & $\begin{array}{l}\text { Unpacking the innovation ecosystem } \\
\text { construct: Evolution, gaps, and trends }\end{array}$ & $\begin{array}{l}\text { This research is to clarify the concept of } \\
\text { the innovation ecosystem, identify trends } \\
\text { and research opportunities }\end{array}$ & $\begin{array}{l}\text { The study conducts a systematic } \\
\text { literature review from } 1993 \text { to } 2016, \\
\text { with a hybrid methodology including } \\
\text { bibliometric and content analysis. }\end{array}$ & $\begin{array}{l}\text { "Business ecosystem" relates mainly to value } \\
\text { capture, while "innovation ecosystem" } \\
\text { relates mainly to value creation. }\end{array}$ \\
\hline 8 & $\begin{array}{c}\text { Managing Ecosystems for Service } \\
\text { Innovation: A Dynamic Capability } \\
\text { View }\end{array}$ & $\begin{array}{l}\text { Adopting an ecosystem and dynamic } \\
\text { capability perspective, this study } \\
\text { examines ecosystem-related capabilities } \\
\text { for developing service innovation in } \\
\text { product-centric firms. }\end{array}$ & $\begin{array}{l}\text { The study uses a mixed-methods } \\
\text { approach focusing on the energy } \\
\text { utility sector. }\end{array}$ & $\begin{array}{l}\text { (1) Firms with high service-in-novation } \\
\text { intensity possess significantly stronger } \\
\text { ecosystem-related capabilities than firms with } \\
\text { lower service- innovation intensity. } \\
\text { (2) Successful service innovators consider not } \\
\text { only value-adding partnerships, such as } \\
\text { suppliers and customers, to be relevant for } \\
\text { service innovation, but also relationships } \\
\text { with non-direct value-adding ecosystem } \\
\text { stakeholders (e.g., local governments, } \\
\text { communities, legislators). }\end{array}$ \\
\hline 9 & $\begin{array}{c}\text { Innovation Ecosystems: A Conceptual } \\
\text { Review and a New Definition }\end{array}$ & $\begin{array}{l}\text { The purpose of the study is to review } \\
\text { received definitions of innovation } \\
\text { ecosystems and related concepts and to } \\
\text { propose a synthesized definition of an } \\
\text { innovation ecosystem. }\end{array}$ & $\begin{array}{l}\text { Conceptual history studies and } \\
\text { literature on methodology for } \\
\text { conceptual analysis. }\end{array}$ & $\begin{array}{l}\text { An innovation ecosystem is the evolving set } \\
\text { of actors, activities, and artifacts, and the } \\
\text { institutions and relations, including } \\
\text { complementary and substitute relations, that } \\
\text { are important for the innovative performance } \\
\text { of an actor or a population of actors. }\end{array}$ \\
\hline
\end{tabular}




\section{References}

1. Ghazinoory, S.; Sarkissian, A.; Farhanchi, M.; Saghafi, F. Renewing a dysfunctional innovation ecosystem: The case of the Lalejin ceramics and pottery. Technovation 2020, 96-97, 102122. [CrossRef]

2. Jiang, S.; Hu, Y.; Wang, Z. Core firm based view on the mechanism of constructing an enterprise innovation ecosystem: A case study of haier group. Sustainability 2019, 11, 3108. [CrossRef]

3. Hu, J.; Ouyang, T.; Wei, W.X.; Cai, J. How do manufacturing enterprises construct e-commerce platforms for sustainable development? a case study of resource orchestration. Sustainability 2020, 12, 6640. [CrossRef]

4. Hakala, H.; O'Shea, G.; Farny, S.; Luoto, S. Re-storying the business, innovation and entrepreneurial ecosystem concepts: The model-narrative review method. Int. J. Manag. Rev. 2019, 22, 10-32. [CrossRef]

5. Yin, D.; Ming, X.; Zhang, X. Sustainable and smart product innovation ecosystem: An integrative status review and future perspectives. J. Clean. Prod. 2020, 274, 12300. [CrossRef]

6. Granstranda, O.; Holgerssonb, M. Innovation ecosystems: A conceptual review and a new definition. Technovation 2020, 90-91, 102098. [CrossRef]

7. Micheli, P. Doing design thinking: Conceptual review, synthesis and research agenda. J. Prod. Innov. Manag. 2019, 36, 124-148. [CrossRef]

8. Gomes, L.A.D.V.; Facin, A.L.F.; Salerno, M.S.; Ikenami, R.K. Unpacking the innovation ecosystem construct: Evolution, gaps and trends. Technol. Forecast. Soc. Chang. 2018, 136, 30-48. [CrossRef]

9. Venkatraman, A.G.A.N. Contingency perspectives of organizational strategy: A critical review of the empirical research. Acad. Manag. Rev. 1985, 10, 421-434.

10. Dedehayir, O.; Mäkinen, S.J.; Ortt, J.R. Roles during innovation ecosystem genesis: A literature review. Technol. Forecast. Soc. Chang. 2018, 136, 18-29. [CrossRef]

11. Lütjen, H.; Schultz, C.; Tietze, F.; Urmetzer, F. Managing ecosystems for service innovation: A dynamic capability view. J. Bus. Res. 2019, 104, 506-519. [CrossRef]

12. Xu, G.; Hu, W.; Qiao, Y.; Zhou, Y. Mapping an innovation ecosystem using network clustering and community identification: A multi-layered framework. Scientometrics 2020, 124, 2057-2081. [CrossRef]

13. Mazzucato, M.; Robinson, D.K.R. Co-creating and directing innovation ecosystems? NASA's changing approach to public-private partnerships in low-earth orbit. Technol. Forecast. Soc. Chang. 2018, 136, 166-177. [CrossRef]

14. Lv, X.; Liu, Y.; Luo, J.; Liu, Y.; Li, C. Does a cute artificial intelligence assistant soften the blow? The impact of cuteness on customer tolerance of assistant service failure. Ann. Tour. Res. 2021, 87, 103114. [CrossRef]

15. Lv, X.; Liu, Y.; Xu, S.; Li, Q. Welcoming host, cozy house? The impact of service attitude on sensory experience. Int. J. Hosp. Manag. 2021, 95, 102949. [CrossRef]

16. Vargo, S.L.; Wieland, H.; Akaka, M.A. Innovation through institutionalization: A service ecosystems perspective. Ind. Mark. Manag. 2015, 44, 63-72. [CrossRef]

17. Arenal, A.; Armuña, C.; Feijoo, C.; Ramos, S.; Xu, Z.; Moreno, A. Innovation ecosystems theory revisited: The case of artificial intelligence in China. Telecommun. Policy 2020, 44, 101960. [CrossRef]

18. Gawer, A. Bridging differing perspectives on technological platforms: Toward an integrative framework. Res. Policy 2014, 43, 1239-1249. [CrossRef]

19. Rong, K.; Liu, Z.; Shi, Y. Reshaping the business ecosystem in China: Case studies and implications. J. Sci. Technol. Policy China 2011, 2, 171-192. [CrossRef]

20. Nambisan, S.; Baron, R.A. Entrepreneurship in innovation ecosystems: Entrepreneurs' self-regulatory processes and their implications for new venture success. Entrep. Theory Pract. 2012, 37, 1071-1097. [CrossRef]

21. Gawer, A.; Cusumano, M.A. Industry platforms and ecosystem innovation. J. Prod. Innov. Manag. 2013, 31, 417-433. [CrossRef]

22. Davis, J.P. The group dynamics of interorganizational relationships. Adm. Sci. Q. 2016, 61, 621-661. [CrossRef]

23. Lv, X.; Wu, A. The role of extraordinary sensory experiences in shaping destination brand love: An empirical study. J. Travel Tour. Mark. 2021, 38, 179-193. [CrossRef]

24. Sun, J.; Lv, X. Feeling dark, seeing dark: Mind-body in dark tourism. Ann. Tour. Res. 2021, 86, 103087. [CrossRef]

25. Huang, H.; Chen, J.; Yu, F.; Zhu, Z. Establishing the enterprises' innovation ecosystem based on dynamics core competence- the case of China's high-speed railway. Emerg. Mark. Financ. Trade 2018, 55, 843-862. [CrossRef]

26. Benitez, G.B.; Ayala, N.F.; Frank, A.G. Industry 4.0 innovation ecosystems: An evolutionary perspective on value cocreation. Int. J. Prod. Econ. 2020, 228, 107735. [CrossRef]

27. Gan, J.; Qi, Y.; Tian, C. The construction and evolution of technological innovation ecosystem of Chinese firms: A case study of LCD technology of CEC Panda. Sustainability 2019, 11, 6373. [CrossRef]

28. Santos, R.; Abreu, A.; Dias, A.; Calado, J.M.F.; Anes, V.; Soares, J. A framework for risk assessment in collaborative networks to promote sustainable systems in innovation ecosystems. Sustainability 2020, 12, 6218. [CrossRef]

29. Zhong, J.; Attour, A.; Burger-Helmchen, T.; Nieminen, M. Resource-based co-innovation through platform ecosystem: Experiences of mobile payment innovation in China. J. Strategy Manag. 2015, 8, 283-298. [CrossRef]

30. Masi, D.; Kumar, V.; Garza-Reyes, J.A.; Godsell, J. Towards a more circular economy: Exploring the awareness, practices, and barriers from a focal firm perspective. Prod. Plan. Control. 2018, 29, 539-550. [CrossRef] 
31. Ubreziova, I.; Diacikova, A.; Sokil, O.; Apostol, S. Innovation ecosystems for the moldovan small and medium-sized enterprises. Mark. Manag. Innov. 2020, 2, 298-312. [CrossRef]

32. Kahle, J.H.; Marcon, É.; Ghezzi, A.; Frank, A.G. Smart products value creation in SMEs innovation ecosystems. Technol. Forecast. Soc. Chang. 2020, 156, 120024. [CrossRef]

33. Reynolds, E.B.; Uygun, Y. Strengthening advanced manufacturing innovation ecosystems: The case of Massachusetts. Technol. Forecast. Soc. Chang. 2018, 136, 178-191. [CrossRef]

34. Li, B.H.; Liu, Y.; Zhang, A.M.; Wang, W.H.; Wan, S. A survey on blocking technology of entity resolution. J. Comput. Sci. Technol. 2020, 35, 769-793. [CrossRef]

35. Hu, J.; Zhang, H.; Liu, L.; Zhu, X.; Zhao, C.; Pan, Q. Convergent multiagent formation control with collision avoidance. IEEE Trans. Robot. 2020, 36, 1805-1818. [CrossRef]

36. Brem, A.; Radziwon, A. Efficient triple helix collaboration fostering local niche innovation projects-A case from Denmark. Technol. Forecast. Soc. Chang. 2017, 123, 130-141. [CrossRef]

37. Hu, J.; Wang, M.; Zhao, C.; Pan, Q.; Du, C. Formation control and collision avoidance for multi-UAV systems based on Voronoi partition. Sci. China Technol. Sci. 2020, 63, 65-72. [CrossRef]

38. Hu, J.; Zhang, H.; Li, Z.; Zhao, C.; Xu, Z.; Pan, Q. Object traversing by monocular UAV in outdoor environment. Asian J. Control 2020, in press. [CrossRef]

39. Wu, J.; Ye, R.; Ding, L.; Lu, C.; Euwema, M. From "transplant with the soil" toward the establishment of the innovation ecosystem: A case study of a leading high-tech company in China. Technol. Forecast. Soc. Chang. 2018, 136, 222-234. [CrossRef]

40. Kwak, K.; Kim, W.; Park, K. Complementary multiplatforms in the growing innovation ecosystem: Evidence from 3D printing technology. Technol. Forecast. Soc. Chang. 2018, 136, 192-207. [CrossRef]

41. Adner, R.; Kapoor, R. Value creation in innovation ecosystems: How the structure of technological interdependence affects firm performance in new technology generations. Strateg. Manag. J. 2010, 31, 306-333. [CrossRef]

42. Ritala, P.; Agouridas, V.; Assimakopoulos, D.; Gies, O. Value creation and capture mechanisms in innovation ecosystems: A comparative case study. Int. J. Technol. Manag. 2013, 63, 244. [CrossRef]

43. Aarikka-Stenroos, L.; Ritala, P. Network management in the era of ecosystems: Systematic review and management framework. Ind. Mark. Manag. 2017, 67, 23-36. [CrossRef]

44. Dattée, B.; Alexy, O.; Autio, E. Maneuvering in poor visibility: How firms play the ecosystem game when uncertainty is high. Acad. Manag. J. 2018, 61, 466-498. [CrossRef]

45. González Fernández, S.; Kubus, R.; Mascareñas Pérez-Iñigo, J. Innovation ecosystems in the EU: Policy evolution and horizon Europe proposal case study (the actors' perspective). Sustainability 2019, 11, 4735. [CrossRef]

46. Pique, J.M.; Berbegal-Mirabent, J.; Etzkowitz, H. Triple Helix and the evolution of ecosystems of innovation: The case of Silicon Valley. Triple Helix 2018, 5, 11. [CrossRef]

47. Gao, Y.; Liu, X.; Ma, X. How do firms meet the challenge of technological change by redesigning innovation ecosystem? A case study of IBM. Technol. Manag. 2019, 80, 241. [CrossRef]

48. Feng, J.; Liu, Z.; Feng, L. Identifying opportunities for sustainable business models in manufacturing: Application of patent analysis and generative topographic mapping. Sustain. Prod. Consum. 2021, 27, 509-522. [CrossRef]

49. Costa, J.; Matias, J.C.O. Open innovation 4.0 as an enhancer of sustainable innovation ecosystems. Sustainability 2020, 12,8112 [CrossRef]

50. Surie, G. Creating the innovation ecosystem for renewable energy via social entrepreneurship: Insights from India. Technol. Forecast. Soc. Chang. 2017, 121, 184-195. [CrossRef]

51. Beltagui, A.; Rosli, A.; Candi, M. Exaptation in a digital innovation ecosystem: The disruptive impacts of 3D printing. Res. Policy 2020, 49, 103833. [CrossRef]

52. Palmié, M.; Wincent, J.; Parida, V.; Caglar, U. The evolution of the financial technology ecosystem: An introduction and agenda for future research on disruptive innovations in ecosystems. Technol. Forecast. Soc. Chang. 2020, 151, 119779. [CrossRef]

53. Walrave, B.; Talmar, M.; Podoynitsyna, K.S.; Romme, A.G.L.; Verbong, G.P.J. A multi-level perspective on innovation ecosystems for path-breaking innovation. Technol. Forecast. Soc. Chang. 2018, 136, 103-113. [CrossRef]

54. Ansari, S.S.; Garud, R.; Kumaraswamy, A. The disruptor's dilemma: TiVo and the U.S. television ecosystem. Strat. Manag. J. 2016, 37, 1829-1853. [CrossRef]

55. Radziwon, A.; Bogers, M. Open innovation in SMEs: Exploring inter-organizational relationships in an ecosystem. Technol. Forecast. Soc. Chang. 2019, 146, 573-587. [CrossRef]

56. Chesbrough, H.; Kim, S.; Agogino, A. Chez panisse: Building an open innovation ecosystem. Calif. Manag. Rev. 2014, 56, 144-171. [CrossRef]

57. Feng, J.; Liu, B.; Liu, Z. Manufacturer's business strategy: Interaction of sharing economy and product rollover. Complexity 2020, 2020, 2328602. [CrossRef]

58. Liu, B.; Yang, G.; Zhang, Q. Pricing decisions and innovation strategies choice in supply chain with competing manufacturers and common supplier. Sustainability 2020, 12, 8855. [CrossRef]

59. Liu, Z.; Xiao, Y.; Feng, J. Manufacturer's sharing servitization transformation and product pricing strategy. Sustainability 2021, 13, 1503.

60. Cao, L. Changing port governance model: Port spatial structure and trade efficiency. J. Coast. Res. 2020, 95, 963-968. [CrossRef] 
61. Klewitz, J.; Hansen, E.G. Sustainability-oriented innovation of SMEs: A systematic review. J. Clean. Prod. 2014, 65, 57-75. [CrossRef]

62. Pucci, T.; Runfola, A.; Guercini, S.; Zanni, L. The role of actors in interactions between "innovation ecosystems": Drivers and implications. IMP J. 2018, 12, 333-345. [CrossRef]

63. Feng, L.; Li, Y.; Liu, Z.; Wang, J. Idea generation and new direction for exploitation technologies of coal-seam gas through recombinative innovation and patent analysis. Int. J. Environ. Res. Public Health 2020, 17, 2928. [CrossRef] [PubMed]

64. Feng, L.; Niu, Y.; Liu, Z.; Wang, J.; Zhang, K. Discovering technology opportunity by keyword-based patent analysis: A hybrid approach of morphology analysis and USIT. Sustainability 2020, 12, 136. [CrossRef]

65. Liu, Z.; Feng, J.; Wang, J. Resource-constrained innovation method for sustainability: Application of morphological analysis and TRIZ inventive principles. Sustainability 2020, 12, 917. [CrossRef]

66. Wu, T.; Xiong, L.; Cheng, J.; Xie, X. New results on stabilization analysis for fuzzy semi-Markov jump chaotic systems with state quantized sampled-data controller. Inform. Sci. 2020, 521, 231-250. [CrossRef]

67. Liu, Y.; Lv, X.; Tang, Z. The impact of mortality salience on quantified self behavior during the COVID-19 pandemic. Pers. Indiv. Differ. 2021, 180, 110972. [CrossRef]

68. Yuan, H.; Wang, Z.; Shi, Y.; Hao, J. A dissipative structure theory-based investigation of a construction and demolition waste minimization system in China. J. Environ. Plann. Man. 2021, 1-27. [CrossRef]

69. Valkokari, K.; Ketonen-Oksi, S. Innovation ecosystems as structures for value co-creation. Technol. Innov. Manag. Rev. 2019, 9, 25-35.

70. Mantovani, A.; Ruiz-Aliseda, F. Equilibrium innovation ecosystems: The dark side of collaborating with complementors. Manag. Sci. 2016, 62, 534-549. [CrossRef]

71. Oh, D.S.; Phillips, F.; Park, S.; Lee, E. Innovation ecosystems: A critical examination. Technovation 2016, 54, 1-6. [CrossRef]

72. Chen, Y.; Chen, Y.; Guo, Y.; Xu, Y. Research on the coordination mechanism of value cocreation of innovation ecosystems: Evidence from a chinese artificial intelligence enterprise. Complexity 2021, 2021, 7629168.

73. Nylund, P.A.; Brem, A.; Agarwal, N. Innovation ecosystems for meeting sustainable development goals: The evolving roles of multinational enterprises. J. Clean. Prod. 2021, 281, 125329. [CrossRef]

74. Shuai, Z.; Haijun, W. Structure and evolution mechanism of the enterprise innovation ecosystem in terms of modularity: A longitudinal case study on Haier Group from 2005 to 2019. Sci. Res. Manag. 2021, 42, 33-46. 